\title{
Precária existência, implacável destino: Machado de Assis, Borges e Poe, em Luis Fernando Verissimo
}

\section{Resumo:}

Enfocando contos e romances de Luis Fernando Verissimo, este ensaio discute a robusta semelhança de aspectos estilísticos e temáticos entre o autor gaúcho e três mestres da narrativa oriundos de diferentes tradições literárias: o estadunidense Edgar Allan Poe, o argentino Jorge Luis Borges, e o brasileiro Joaquim Maria Machado de Assis. Exploram-se as facetas que dão coesão e dinamismo crítico ao tipo de escrita estranha e desconcertante praticada por Verissimo. Sua narrativa, como tal, emprega narradores extremamente criativos. Eles não apenas questionam a própria linguagem humana e negociam conexões simbólicas e coincidências entrecortadas entre vida e arte. Mesclam-se, também, fatos e ficções, mitos clássicos e afazeres banais, que, muito amiúde, se fundem em meio ao bizarro e ao imponderável nos eventos do dia-a-dia.

Palavras-chave: Luis Fernando Verissimo, Edgar Allan Poe, Jorge Luis Borges, Joaquim Maria Machado de Assis

\footnotetext{
Abstract:

Precarious Existence, Implacable Fate: Machado de Assis, Borges and Poe, in Luis Fernando Verissimo

Focusing on short stories and novels by Luis Fernando Verissimo, this essay discusses the robust similarities between stylistic and thematic aspects of the Gaúcho author's writing and those of three masters of the narrative who come from different literary traditions: the United States writer Edgar Allan Poe, the Argentinean
} 
Dário Borim Jr.

Jorge Luis Borges, and the Brazilian Joaquim Maria Machado de Assis. The study explores facets that afford cohesion and critical vitality in Verissimo's strange and disconcerting writing. His narrative as such employs narrators extremely creative. They not only question human language itself and negotiate symbolic connections and intertwined coincidences between life and art, but also mingle facts and fictions, classic myths mundane deeds, which, quite often, fuse themselves in the midst of the bizarre and the imponderable in daily life.

Keywords: Luis Fernando Verissimo, Edgar Allan Poe, Jorge Luis Borges, Machado de Assis

Há uma robusta semelhança, quanto a aspectos estilísticos e ênfase temática, entre o autor Luis Fernando Verissimo e três mestres da narrativas de três diferentes tradições literárias: o brasileiro Joaquim Maria Machado de Assis, o argentino Jorge Luis Borges, e o estadunidense Edgar Allan Poe. Neste ensaio almeja-se explorar facetas que na obra do autor gaúcho refletem atributos marcantes do legado literário deixado pelos três mestres da narrativa do social articulado e criticado pelas vias da irreverência e do pessimismo, do absurdo e do deboche, do suspense e da comicidade.

O macabro e o impensável, os impulsos sem piedade mas divertidos do humor negro, e as reviravoltas inteligentes dos bons contadores de histórias são ingredientes embalados nas expectativas mirabolantes e nos enredos típicos de pesadelos que tantas vezes tematizam as indelicadezas humanas. Todos esses traços em Borges e os orangotangos eternos, romance de 2000, por exemplo, ecoam o estilo denso, paródico, provocador e imprevisível da escrita do autor estadonidense. O romance é ponto central na dissertação de doutorado de Carla Castano, que investiga a influência de Borges sobre três escritores do Brasil e Equador, especialmente a relação entre tempo e espaço, e certos princípios de Harold Bloom sobre influência literária, figuras geométricas e campo visual. Verissimo lá expõe sua forte queda para as narrativas de mistério e suspense em textos voltados para variados crimes, com tropos literários em comum com os de Poe, cuja obra orienta um dos contextos e temas mais proeminentes daquele romance. 
Para Nelson Vieira, o autor gaúcho se inspira na noção borgeana de que tudo para de fato existir carece de pelo menos uma palavra que o defina. É esse conceito que "perversamente domina e finalmente resolve a trama desse sarcástico, enfeitiçado e espirituoso romance" (2016: 70). Vieira não se engana: o romance é "uma óbvia homenagem a Jorge Luis Borges e Edgar Allan Poe" (2016: 70). Na visão do crítico da Universidade Brown, o que se descortina é uma paródia das narrativas de crime compostas por Borges, especialmente "La muerte y la brújula", de 1942, e "uma saudação intertextual" a Poe, em particular "The Murders in the Rue Morgue", de 1841 (2016: 70). A narrativa de Verissimo brinca com "as pistas esotéricas e metáforas eruditas tão características da ficção borgeana carregada de simbolismo" (2016: 70). O livro também atira farpas no egocentrismo acadêmico, controle autoral, e análises crípticas, questões levantadas, argumenta Vieira, pela fictícia Sociedade Israfel, exclusivamente dedicada aos estudos e interpretações da ficção de Poe (2016: 71).

No que aparece no romance de Verissimo como teatro conflitivo e egocêntrico, tipicamente observável nas interpretações acadêmicas de obras literárias canônicas, há espaço para teses contraditórias sobre Edgar Allan Poe. Destaca-se a noção do pesquisador Joachim Rotkopt de que a criatividade de Poe representava "a dissolução final, na necrofilia e na loucura, da imaginação gótica, o último suspiro da sensibilidade europeia na fronteira selvagem, 'antes de ser comida pelos búfalos"' (Verissimo, 2000: 24). Dentro dessa mesma perspectiva, era difícil afirmar "quem estuprara quem" na história das relações entre a Europa e as Américas (Verissimo, 2000: 24). Além do mais, foi a partir das ruínas em decomposição do que fora o gótico, deixadas pelos europeus nas Américas, que o surrealismo tomou vulto no Velho Continente. Talvez, tal surrealismo não tenha sido mais que a "resposta europeia para o surrealismo inconsciente do Novo Mundo" (Verissimo, 2000: 24). Para o professor Rotkopf, um dos protagonistas da trama, o verdadeiro Poe era o Poe traduzido para o francês por Baudelaire, o "Poe resgatado dos bárbaros para revitalizar a vanguarda europeia" (24). 
Verissimo sem dúvida apresenta intensa utilização de elementos considerados marcas do fantástico, em ressonância com uma bizarra mistura de erudição, ironia, espirituosidade e sarcasmo que encontramos no vanguardista argentino Jorge Luis Borges, ele próprio ficcionalizado em forma de personagem principal e de parcial narrador naquele romance de Verissimo. Vogelstein, o escritor que narra a maior parte do enredo, é um sujeito profissionalmente frustrado e neuroticamente obcecado com a literatura de Borges. A certo ponto na trama, encontra-se solitário e levado por seus próprios sonhos no interior da biblioteca do autor que tanto admira, em Buenos Aires. Mais tarde, endereçando o discurso ao próprio Borges, o narrador confessa que finalmente tinha a chance de lhe dirigir a palavra face a face, fora de qualquer sonho: "Com a compunção e o deleite disputando o poder no seu rosto, a náusea e o êxtase disputavam o domínio do meu estômago" (Verissimo, 2000: 43).

Protagonista de outra história, "No céu", um breve conto na antologia Banquete com os deuses, de 2002, Jorge Luis Borges morre e vai para o céu, junto com Ítalo Calvino e Vladimir Nabokov, para reconhecer e celebrar as belezas daquele idílico lugar. Afinal de contas, reflete a voz que narra, a ideia que se tem do destino dos mortos "foi certamente o primeiro produto da imaginação do homem, seu primeiro esforço literário" (Verissimo 2003: 157). O próprio Calvino, apesar de ser ateu (acrescenta o narrador), pensava que era sua obrigação ir para lá. Calvino concordava com a noção de que todos os escritores para o céu se dirigiam por conta de seus inegáveis direitos depois de seguir carreiras nas letras, inclusive o Marquês de Sade. Todos viravam anjos, embora esse, o Marquês, ocupasse um espaço cercado e tivesse "as asas curtas como as de uma galinha" (Verissimo, 2003: 157).

Nos terrenos celestiais, os três autores discutem vários temas polêmicos em relação ao mundo literário, como, por exemplo, obstruir carreiras de escritores inúteis, enganados ou mal direcionados. Uma solução, concordavam os três, seria conceder a certos críticos o direito de condenar tais pobres escritores à deriva, até mesmo à morte. Os próprios críticos se encarregariam de executá-los, uma tarefa que 
contribuiria para o aprimoramento dos seus métodos e critérios exegéticos (Verissimo, 2003: 157).

Revertendo o veneno de sua sátira sobre o mundo dos autores canônicos, o narrador conclui sua história. Borges ao final diria que a frase mais sensual que tinha lido em toda a sua vida vinha de um poema curdo. Depois de Borges recitar tal verso, "Kodem tzamas dosmas dur badram" (certamente non-sense), Calvino e Nabokov sorriram um para o outro. Esperavam pela tradução dos mesmos, e nada. Então Borges "revelou que não tinha a menor ideia do seu significado, apenas tivera uma ereção ao lê-los" (Verissimo, 2003: 158).

Múltiplas semelhanças ocorrem, livro após livro, entre Verissimo e outro excêntrico e prolífico autor, Machado de Assis. Isso evidencia-se especialmente através da utilização de narradores duvidosos e personagens amorais, além de outras estratégias narratológicas que fraturam ou desafiam os atributos de gênero específicos, como a identificação linear autor-narrador-protagonista tão comum nas crônicas convencionais, ou como a interferência mútua entre diferentes linhas do enredo, como se dispõe no romance de estreia de Verissimo, Ojardim do diabo, 1987.

Ali Verissimo entrelaça a linha do enredo que corre pelos sons de uma estação de rádio com a linha mestra do romance, que se desenrola pelas mãos do autor-narrador-protagonista, Estevão. Às vezes essa mesma via dupla se torna tripla, pois ao mesmo tempo em que se misturam, chega ao ambiente de casa um detetive policial que investiga Estevão. Diz este que são estranhíssimas as coincidências entre alguns crimes da vida real discutidos no programa de rádio e as tramas criadas por aquele autor de romances policiais de baratas edições de bolso vendidas em bancas de revistas, inclusive a trama do romance que o próprio Estevão está escrevendo naquela mesma hora. Tal trama é conhecida por nós, leitores de O jardim do diabo, já que Estevão a comenta, mas ela é ignorada pelos outros personagens da narrativa que lemos, como também por aqueles da obra que evolui por dentro daquela.

O livro de detetives, sendo aos poucos redigido dentro do romance que temos em mãos, é composto de múltiplos personagens cujos 
nomes e concepções se amarram por fortes laços literários e artísticos. Ortega e Gasset são dois balconistas irlandeses que trabalham num bar-restaurante onde empresários do tráfico de drogas e de armas se sociabilizam e conduzem seus negócios. García Márquez, nesse contexto ficcional, é o maior produtor e fornecedor de cocaína em todo o mundo. Grego, outro gangster de colarinho branco, sugere que 10\% do lucro obtido pelos homens ali presentes no restaurante seriam capazes de salvar o mundo da fome (Verissimo 2005: 135). Mas não se importam, logicamente, tampouco se parecem com monstros. Na maioria eram homens "com mais de quarenta anos, bem-vestidos. Executivos, profissionais liberais, talvez alguns do mundo dos espetáculos", informa o narrador (Verissimo 2005: 135).

Grego pensa que a maioria das pessoas no mundo do crime não são culpadas. São inocentes no sentido de que o que fazem é ritual, sem meio-termo. É fruto de uma necessidade cega de agir sem misericórdia: "Coisas vivas comem coisas mortas, ou semivivas, e as metabolizam para viver. O que sobra é lixo, é excremento. Isto tudo seria de muito mau gosto se houvesse uma alternativa. Mas não há, é assim que somos feitos" (Verissimo, 2005: 139). Pessoas daquele grupo no restaurante, continua Grego, reagem a uma fome mundial. Algumas partes do planeta têm fome de armas para lidar com suas diferenças. Outras partes do mundo têm fome de drogas, para êxtase ou desejada amnésia. "Armas e drogas são metabolizadas e o que sobra são cadáveres. O lixo, é excremento. Isto não é moral ou imoral, é o mundo" (Verissimo, 2005: 139). Quando a comida chega àquela mesa de bandidos, Grego diz a Conrad James: "Não seja vaidoso. Coma. Minha mãe dizia: 'Morra de barriga cheia e faça pelo menos alguns vermes felizes"' (Verissimo, 2005: 140).

Em clima de humor e ironia, questões de ética e filosofia, além de literatura e arte, muito ao gosto de Machado de Assis, fazem a conexão entre os poderes e os percalços de um escritor profissional de imaginação irrestrita e completamente aberta, uma imagem evocada por um personagem e representada pelo título do livro. De acordo com o padre José, o "jardim do diabo" é o nosso estado mental quando temos tempo e livre arbítrio para pensar. "A mente ociosa é o jardim 
do diabo", reitera o sacerdote (Verissimo, 2005: 54). Na condição de instrutor de catequismo, esse mesmo padre tinha insistido com Estevão para que jamais pensasse nos mistérios do catolicismo - por exemplo, a co-existência da Santa Trindade. Ecoando Machado de Assis nas suas sardônicas sátiras sobre o clero, ideias religiosas conservadoras e seus laços estreitos com a política repressiva da época estão profundamente mescladas, onde Verissimo mais uma vez revisita os tempos tenebrosos da ditadura militar mais recente no Brasil.

Aquele período da história caracterizado por métodos draconianos de coerção e terror anti-comunista patrocinados pelo Estado, além de ostensiva censura na mídia, escolas, e artes, também é o pano-de-fundo de muitos outros textos de Verissimo, entre eles o dramático conto "A Mancha", da coleção Os últimos quartetos de Beethoven e outros contos, de 2013. Segundo um instigante estudo de Leila Lehman, a narrativa faz uma representação dos "locais esquizofrênicos da memória", conceito que engloba um palimpsesto de "várias (e muitas vezes contraditórias) versões do passado" (2014: 73). A palavra "mancha" do título do conto é associada a uma desconcertante marca de sangue deixada numa parede suja de um prédio abandonado, mas também está simbolicamente ligada a experiências passadas da sociedade brasileira. Rogério - antes, um ativista socialista; hoje, um empreendedor na área de imóveis - descobre tal marca vermelha exatamente onde ele e outros ativistas tinham sido torturados pela polícia política do país nos anos 70 .

De fato, Veríssimo aproxima-se das inesgotáveis e misteriosas fontes de imaginação a la Machado de Assis, especialmente quando o escritor carioca em 1886 escreve uma série de crônicas intituladas "A + B" e originalmente divulgadas no jornal Gazeta de Notícias, todas em forma de diálogos entre sujeitos anônimos, às bordas ou além do inverossímil. No caso do autor gaúcho, temos 45 textos curtos que em Diálogos impossiveis, de 2012, transcrevem, humoristicamente, conversas entre seres díspares, tanto do mundo real quanto do mundo das artes plásticas e da ficção literária e cinematográfica.

$\mathrm{Na}$ abertura do volume encontra-se "A diferença". Tomando café da manhã, Batman, o justiceiro da capa preta, e Drácula, o vampiro 
desalmado, discutem vida e morte, bondade e maldade, e muito mais, numa casa para idosos na Suíça. Enquanto vampiro, Drácula está deprimido e cansado de viver, mas, por sua natureza espírita, não pode morrer. Está envergonhado de sua dentadura protética e é extremamente óbvia a decadência de sua aparência. Batman também se vê no fundo do poço, pois não pode mais caminhar ou renovar sua carteira de motorista. Em contraste à disposição de Drácula, que lamenta a condição de martírio sem fim, Batman gostaria de viver eternamente, mas sabe que seu fim está próximo.

Em "Estátuas", outro conto montado sobre estranhíssima conversa entre agentes de diferentes esferas, as reais estátuas de bronze de Carlos Drummond de Andrade (no Rio de Janeiro), Fernando Pessoa (em Lisboa), e Mário Quintana (em Porto Alegre) refletem sobre os dilemas e as angústias de existir enquanto monumentos desolados e silenciosos. Nas asas da licença poética que os constrói, Quintana e Drummond visitam Pessoa junto ao café A Brasileira, num lendário bairro de Lisboa, onde a frustração rola solta entre os bardos imobilizados em puro metal que não lhes dá qualquer chance de viver como viviam outrora. "Pessoa" - diria Drummond -, "estamos há meia hora com você nesta mesa do Chiado, e você não nos ofereceu nem um cafezinho" (2012: 157). "Não posso" - respondia Pessoa. "Não consigo chamar o garçom. Não consigo me mexer. Muito menos estalar os dedos". Então Pessoa confessa: "Não posso reagir quando sentam à minha volta para serem fotografados, ou retribuir quando me abraçam, ou espantar as crianças que me chutam, ou protestar quando um turista diz, 'Olha o Eça de Queiroz"” (Verissimo 2012: 157). "Em Copacabana é pior" - argumenta Drummond, que acrescenta: "Fico de costas para a praia, só ouvindo o ruído do mar e o tintilar das mulheres, sem poder me virar". "Pior mesmo" - diria Quintana - "é estar cheio de poemas ainda não escritos e não poder escrevê-los, nem em cima da perna". Os três bardos concordaram em pelo menos alguns pontos fundamentais: "O pior é serem poetas eternos, monumentos de bronze à prova das agressões do tempo, fora a poluição e o vandalismo - e não poderem escrever nem sobre isto. As estátuas de poetas são a sucata da poesia" (Verissimo 2012: 157). 
Vemos, assim, que as facetas que compõe uma vasta estrutura de humor que dá coesão e dinamismo ao tipo de escrita estranha, desconcertante e iconoclasta praticada por Verissimo desde a década de 1970 dialogam, em muitos níveis, inclusive nos planos formal e filosófico, com a arte de Machado de Assis, Borges e Poe. A narrativa de Verissimo, como tal, muitas vezes emprega narradores extremamente criativos que questionam a própria linguagem humana, ou que negociam as conexões simbólicas e coincidências entrecortadas que relacionam a vida à arte, fatos e ficções, mitos clássicos e afazeres banais, como se retratam os romances $O$ jardim do diabo e Borges e os orangotangos eternos. Também, muito amiúde, leitores e personagens fictícios se estarrecem diante do bizarro e do imponderável nos eventos do dia-a-dia, tal como diante do universo sem limites nos contos de Banquete com os deuses, Diálogos impossíveis e Os últimos quartetos de Beethoven.

São esses, consequentemente, os temas de Verissimo e de grandes obras literárias de vários séculos. Eles surgem e ressurgem, por exemplo, em obtusas manifestações de disposições lógicas, aleatórias ou premeditadas da maldade no comportamento de pessoas ditas "normais". Escondem-se tanto nas voltas e reviravoltas das mentiras generalizadas e na má-fé, quanto na responsabilidade e na consciência de culpa da precária existência humana - no que nela há de desgraça implacável, pois está destinada a desparecer a qualquer momento, a qualquer canto, sem muito o que se compreender, consentir, ou controlar.

\section{Referências bibliográficas}

BORGES, J. L. (1944), “La muerte y la brújula” em: Borges, J. L., Ficciones, Sur, Buenos Aires, pp. 499-507.

CASTANO, C. (2018), The Borgesian Garden: Luis Fernando Verissimo, Chico Buarque and Luis Aguilar Monsalve, Dissertação de Ph.D, West Lafayette, IN, Purdue University.

LEHNEN, L. (2014), "Memórias manchadas e ruínas memoriais em A mancha e 'O condomínio', de Luis Fernando Verissimo", Estu- 
dos de Literatura Brasileira, 43, Brasília, pp. 69-97, https://www.doi. org/10.1590/S2316-40182014000100005.

MACHADO de ASSIS, J. M. (2011), Crônicas: $A+B$, Editorial PUC-Rio/ Loyola, Rio de Janeiro-São Paulo.

POE, E. A., "The Murders in the Rue Morgue", [on-line] http://poestories. com/text.php?file=murders -10.10 .2018 .

VERISSIMO, L. F. (2000), Borges e os orangotangos eternos, Companhia das Letras, São Paulo.

VERISSIMO, L. F. (2003), Banquete com os deuses, Objetiva, Rio de Janeiro.

VERISSIMO, L. F. (2005), O jardim do diabo, Objetiva, Rio de Janeiro.

VERISSIMO, L. F. (2012), Diálogos impossíveis, Objetiva, Rio de Janeiro.

VERISSIMO, L. F. (2013), Os últimos quartetos de Beethoven e outros contos, Objetiva, Rio de Janeiro.

VIEIRA, N. H. (2016), "Borges and the Eternal Orangutans", World Literature Today, 80 (5), pp. 70-71. 